\title{
APROXIMAÇÕES ENTRE SEMIÓTICA GREIMASIANA E TEORIA DOS BLOCOS SEMÂNTICOS
}

Doutoranda em Letras - Linguística - pela Universidade Presbiteriana Mackenzie SP. Professora do Curso de Letras da Faplan/Anhanguera-RS.

\section{RESUMO}

A Teoria Semiótica Greimasiana (Algirdas Julien Greimas) e a Teoria do Blocos Semânticos (Carel e Ducrot) são ambas teorias semântico-discursivas de base estruturalista. A partir de comparações entre as duas teorias, podem-se perceber algumas semelhanças (ou pelo menos aproximações) entre elas no que tange às formas como propõem a estruturação semântica das unidades mínimas de composição do sentido. Nesse contexto, o objetivo deste estudo é, a partir da análise da semântica de base de um texto-proposta, tecer aproximações entre a estrutura do nível fundamental da Semiótica e a estrutura dos blocos semânticos da TBS.

Palavras-chave: Teorias semântico-discursivas, Semiótica greimasiana, Teoria dos blocos semânticos (TBS), aproximações entre TBS e Semiótica.

\begin{abstract}
The Greimasianian Semiotics (Algirdas Julien Greimas) and the Theory of the Semantic (Carel and Ducrot) Blocks are both semantic-discursive theories that arise from structuralism. Starting from comparisons between the two theories, some similarities (or at least approaches) can be noticed between them in what concerns the ways they propose the semantic structuring of the minimum units of composition of the sense. In that context, the objective of this study is, from the analysis of the basis semantics of a chosen text, to explore approximation possibilities between the structure of the fundamental level of the Semiotics and the structure of the semantic blocks of TBS.
\end{abstract}

Keywords: Semantic-discursive theories, Greimasianan Semiotics, Theory of the Semantic Blocks (TBS), approximation possibilities between TBS and Semiotics.

\section{INTRODUÇÃO}

A proposta deste trabalho é realizar uma aproximação entre duas teorias semânticodiscursivas, a Teoria Semiótica Greimasiana, cujo precursor é Algirdas Julien Greimas, e a Teoria dos Blocos Semânticos (TBS), desenvolvida pro Oswald Ducrot e Marion Carel. Tal interesse se deve ao fato de ambas serem teorias estruturalistas, que buscam na língua e pela língua explicar os sentidos dos discursos, além de proporem formas semelhantes de estruturação semântica das unidades mínimas de composição do sentido.

Para clarear os conceitos, este estudo se propõe analisar um texto à luz dos fundamentos tanto da semiótica quanto da TBS e, a partir dele, estabelecer as relações de proximidade entre as teorias. É oportuno mencionar, entretanto, que embora a teoria semiótica proponha três níveis de estruturação de um texto - fundamental, narrativo e discursivo - o nível que ora interessa e que será abordado na análise é apenas o fundamental, uma vez que é este nível o que compreende as estruturas semânticas de base de um texto e cuja estruturação permite analogias com a TBS .

Assim, este trabalho se organiza da seguinte forma: primeiramente se apresentam os preceitos básicos da Teoria Semiótica Greimasiana; a seguir, os preceitos básicos da Teoria dos Blocos Semânticos; na seqüência, procede-se à análise de um texto-proposta de acordo com os princípios de cada teoria; e, por fim, às aproximações entre Semiótica e TBS.

\section{TEORIA SEMIÓTICA: ABORDAGEM PANORÂMICA}

Um texto surge da união de um plano de conteúdo com um plano de expressão (verbal, nãoverbal, pictórico, sincrético, etc.) e esses dois planos podem ser estudados separadamente, até porque um mesmo plano de conteúdo pode ser veiculado por diferentes planos de expressão (por exemplo a obra $O$ quatrilho, de José Celemente Pozzenato, vem manifesta por um livro, por um filme e por uma peça teatral e poderia ser traduzida por outros recursos de expressão). 
A teoria semiótica francesa ${ }^{[1]}$, desenvolvida por Algirdas Julien Greimas, concebe o texto como um simulacro do mundo real, uma vez que nele são representados sujeitos, fatos, objetos, valores que retraram o mundo. O texto é, então, um objeto por mieo do qual pode-se entrender as relações que se estabelecem na vida dos homens. Esta teoria "procura descrever e explicar o que o texto diz e como ele faz para dizer o que diz" (BARROS, 2000, p. 7), ou seja, procura explicar o sentido do texto pelo exame de seu plano de conteúdo. Preconiza que, nos limites do plano de conteúdo, o processo de produção dos sentidos de um texto obedece a um percurso gerativo, chamado "percurso gerativo de sentido", que, partindo de informação semânticas simples, abstrata e unitária, gera, por enriquecimentos semânticos sucessivos, estruturas significativas cada vez mais complexas, abstrata e diversificadas. Na verdade,

O percurso gerativo de sentido não tem um estatuto ontológico, ou seja, não se afirma que o falante na produção do texto passe de um patamar ao outro num processo de complexificação semântica. Constitui ele um simulacro metodológico, para explicitar o processo de entendimento, em que o leitor precisa fazer abstrações a partir da superfície do texto, para poder entendê-lo (FIORIN, 1995, p. 165).

Esse percurso gerativo de sentido compreende três níveis de organização dos sentidos de um texto: o nível fundamental, o narrativo e o discursivo. Vejamos, de forma sucinta ${ }^{[2]}$, como se constroem os sentidos do texto em cada um deles.

\subsection{Nível Discursivo}

O nível discursivo é também chamado de nível superficial [3]. É no nível discursivo que as formas abstratas do nível narrativo são revestidas de termos que lhes dão concretude. Os sujeitos, os objetos, as transformações de estado, as competências, entre outros, aspectos do nível narrativo passam aqui a ser representados por temas e/ou figuras, caracterizado dois níveis de concretização das estruturas narrativas: a tematização e afigurativização. Por exemplo, os sujeitos do nível narrativo ganham, no nível discursivo, nomes e se tornam personagens (atores reais ou fictícios) do texto. Além disso, é nesse nível que se estabelecem ainda as categorias de tempo, de espaço e de pessoa, que se produzem os efeitos de verdade, de realidade, de subjetividade/objetividade, de generalização, de aproximação, etc. Enfim, é no nível discursivo que estão "representadas" todas as escolhas feitas pelo enunciador no sentido de persuadir o enunciatário a aceitar/crer no seu discurso. Por isso é que se define o nível discursivo como o mais complexo e mais concreto de todos.

É relevante mencionar que o sujeito da enunciação, ao produzir seu discurso (texto), parte do mais simples e abstrato - estrutura fundamental - para o mais concreto e complexo - o nível discursivo. Já o leitor, na interpretação, faz o caminho inverso, pois parte do nível discursivo, que é como o texto se lhe apresenta, precisando chegar ao nível fundamental.

\subsection{Nível Narrativo}

A segunda etapa do percurso gerativo do sentido compreende o nível narrativo ${ }^{[4]}$. Não se deve pensar, porém, que o percurso gerativo do sentido se aplique somente a textos narrativos. Para a semiótica, todos os textos apresentam narrativas mínimas, que se definem como uma transformação de estado, mesmo que essa transformação esteja implícita e precise ser pressuposta pelo leitor. Ou seja, ocorre uma narrativa mínima, quando se tem um estado inicial, uma transformação e um estado final.

No nível narrativo, aparecem dois tipos de enunciados elementares: os de estado e os de fazer. Conforme Fiorin (2000), os enunciados de estado são os que estabelecem uma relação de junção - conjunção(posse) ou disjunção (privação) - entre um sujeito um objeto-valor ${ }^{[5]}$. Por exemplo, no enunciado "Marta é rica", temos uma relação de conjunção (posse) entre o sujeito 
"Marta" e o objeto-valor "riqueza". No enunciado "Marta não é rica" temos uma relação de disjunção(privação) entre o sujeito e o objeto. Os enunciados de fazer mostram as transformações correspondentes à passagem de um enunciado de estado a outro diferente do inicial: "Marta ganhou na loteria e ficou rica".

Os textos, entretanto, não são narrativas mínimas, mas narrativas complexas, pois são formados por uma série de enunciados de estado e de fazer organizados hierarquicamente. Uma narrativa complexa, quando estruturada numa seqüência canônica, apresenta quatro fases: $a$ manipulação, a competência, a performance e a sanção. No entanto, raramente um texto apresenta todas essas quatro fases explícitas e bem arranjadas. Em geral, elas ficam implícitas e devem ser recuperadas através de pressuposições feitas pelo leitor. Além disso, há textos que focam apenas uma das fases - como os textos de opinião, por exemplo, que geralmente apresentam a sanção -, ou se organizam de forma diferente, sem ser nessa ordem de apresentação.

Em suma, o mais importante é entender que no nível narrativo se estabelecem os jogos de força entre os sujeitos do texto. Nesse nível, basicamente, as personagens e figuras do nível superficial adquirem um grau maior de abstração, tornando-se sujeitos que "disputam" objetosvalores com os quais entram em conjunção/disjunção.

Assim, se no nível discursivo tem-se um enunciado elementar como "Marta ganhou na loteria e ficou rica", no nível narrativo "Marta" configura um "sujeito" que passa de um estado de "disjunção" com um "objeto-valor" (riqueza) para um estado de "conjunção" com o objeto-valor. Esse programa narrativo passa a ser representado por: $\mathbf{S} \mathbf{U}$ Ov à $\mathbf{S} \cap \mathbf{O v}$, onde: $\mathrm{S}=$ sujeito

$$
\text { Ov = objeto valor }
$$

$\mathrm{U}=$ estado de conjunção à = transformação

$\cap=$ estado de disjunção

\subsection{Nível Fundamental}

No nível fundamental (ou estrutura profunda), "determina-se o mínimo de sentido a partir de que o discurso se constrói” (BARROS, 2000, p. 77). Nesse nível, a significação do texto (semântica) aparece determinada pela relação de oposição entre dois termos que possuem um traço semântico em comum, por exemplo: vida x morte; liberdade x opressão, etc.. Um desses termos será sempre eufórico (positivo) e outro disfórico (negativo). No entanto, não é o leitor quem determina qual termo é o eufórico e qual o disfórico, pois esses valores estão inscritos no texto de acordo com o que o enunciador pretende defender. Por exemplo, se, num determinado texto, o autor quer celebrar a vida e repudiar a morte, ele construirá seu texto de forma que a vida seja o termo eufórico e a morte o disfórico. Pode-se ter o contrário dessa situação. Se um autor deseja celebrar a morte e não a vida, o seu texto terá como termo eufórico a morte e como disfórico a vida.

Ainda é importante mencionar que os dois termos contrários que constituem o nível fundamental de um texto obedecem a um percurso específico (sintaxe), que se traduz da seguinte forma: afirmação de um termo A; negação desse termo A; afirmação de um termo B (FIORIN, 2000).

Conforme Barros (2000), para tornar-se operatória, a estrutura elementar é representada por um modelo lógico, o quadrado semiótico. Por exemplo, num texto cuja relação semântica de base fosse vida versus morte, seria o seguinte o quadrado semiótico:

vida B---------à morte

não-morte ß----------à não-vida

Onde:

B------à relação entre contários

relação entre contraditórios

relação entre complementares.

Ainda, o conteúdo fundamental de um texto apresenta-se sob a forma de relações orientadas. A 
orientação das relações é condição primeira da narratividade. Nesse sentido, as possibilidades de organização (sintaxe) de um texto cujo nível fundamental fosse vida vs morte poderiam ser:

A: Afirmação da vida à negação da vida (não-vida) à afirmação da morte OU

B: Afirmação da morte à negação da morte (não-morte) à afirmação da vida

A orientação A ou B do percurso não depende da vontade do leitor, mas está inscrita no texto, cabe ao leitor captá-la e compreendê-la enquanto forma de organização fundamental do texto. Basicamente, é assim que se concebe a estrutura profunda.

\section{TEORIA DOS BLOCOS SEMÂNTICOS: PRINCÍPIOS BASILARES}

A Teoria dos Blocos Semânticos (TBS), atualmente desenvolvida por Marion Carel e Oswald Ducrot - e que tem com base a Teoria da Argumentação na Língua (ADL) ${ }^{[6]}$, desenvolvida inicialmente por Ducrot e Jean Claude Anscombre - é um modelo que se propõe estudar a linguagem tendo como unidade de sentido o enunciado.

É uma teoria estruturalista que entende que o sentido de um enunciado pode ser definido somente na e pela inter-relação das unidades (segmentos) desse enunciado. Ou seja, Ducrot busca no próprio enunciado (e não fora dele, em relações pragmáticas) o seu significado.

Nas palavras de Ducrot, a TBS

[...] busca llevar hasta sus últimas consecuencias las ideas de Saussure, a saber, que el sentido de uma entidad lingüística no es un concepto, no es una idea, ni un hecho material, ni un objeto, sino simplemente um conjunto de relaciones entre esa entidad y las otras entidades de la lengua. [...] Para la TBS, el sentido de uma expresión cualquiera, sea ella palabra o enunciado, está constituído por los discursos que esa expresion evoca. A estos llamamos encadenamientos argumentativos (CAREL e DUCROT, 2005, p. 29)

Vale lembrar que, na TBS, argumentar não é sinônimo de justificar ${ }^{[7]}$. Carel (2005) propõe trabalhar com UMA noção de argumentação puramente discursiva. Argumentação essa que decorre de encadeamentos argumentativos.

\subsection{Encadeamento argumentativo e sentido dos enunciados}

Ducrot entende que o sentido de um enunciado não está associado às informações nele dispostas, mas sim aos encadeamentos que podem ser agregados aos segmentos desse enunciado (CAREL e DUCROT, 2005, p. 13). Carel define encadeamento argumentativo como "qualquer seqüência de dois segmentos que sejam, entre si, dependentes" (2005, p.77).

Um enunciado é, então, a realização de um encadeamento argumentativo, que, por sua vez, é uma unidade semântica. Mais, o sentido de um enunciado decorre exatamente da interdependência semântica entre os segmentos que o compõem.

Assim, num enunciado como "É tarde. Vamos para casa.", há uma relação de interdependência semântica entre os dois segmentos, já que ir para casa está relacionada ao fato de ser tarde. Qual seria o sentido, por exemplo, do primeiro segmento se isolado de qualquer outro? Se se dissesse apenas "É tarde", qual seria o sentido dessa oração?

Em contrapartida, também se poderia dizer "É tarde. Vamos ficar aqui". Também aqui há interdependência semântica, pois, nesse caso, ficar onde está se deve ao fato de ser tarde.

Perceba-se, ainda, que, nos dois enunciados, o mesmo segmento "É tarde" assume sentidos distintos. No primeiro, a concepção de tarde está relacionada com a idéia de que se deve ir para casa após um determinado horário. No segundo, relaciona-se à idéia de que não se deve sair de casa (ou ir para rua) após um determinado horário. Ora, os sentidos diferentes atribuídos a "É tarde" decorrem da interdependência semântica existente entre os dois segmentos que constituem cada um dos encadeamentos. Assim, o sentido de um enunciado somente se constrói no e pelo encadeamento, entendido aqui como encadeamento argumentativo. 


\subsection{Encadeamentos argumentativos normativos e transgressivos}

Segundo Ducrot, a forma geral que esquematiza os encadeamentos argumentativos é: $X$ CONECTOR Y (CAREL e DUCROT, 2005, p.14). Um encadeamento argumentativo está constituído, então, por dois segmentos, $\mathrm{X}$ e $\mathrm{Y}$, unidos por um conector.

A TBS somente admite dois tipos de conectores e, portanto, somente dois tipos de encadeamentos argumentativos: os normativos, com conectores do tipo donc (portanto), e os transgressivos, com conectores do tipo pourtant (mesmo assim) [8].

Um encadeamento normativo tem a estrutura $X$ portanto $Y$, e um encadeamento transgressivo, a estrutura $X$ mesmo assim $Y$. Contudo, um encadeamento normativo não necessariamente está marcado pelo conector "portanto". Pode aparecer sem o conector (como o exemplo mencionado na seção 2.1), ou vir marcado por outro conector que expresse a mesma idéia de "portanto" (então, se, já que, etc.). Também o encadeamento transgressivo pode vir marcado por outras expressões semelhantes a "mesmo assim", como: "ainda que", "mesmo que", "por mais que", "apesar de", etc.

Por exemplo, o enunciado (1) É tarde, portanto vamos para casa, constitui um encadeamento normativo. Já o enunciado (2) É tarde, mesmo assim não vamos para casa, é transgressivo.

Poderia se dizer também (3) É tarde, portanto não vamos para casa. Nesse caso, também se teria um encadeamento normativo, cujo sentido argumentativo é totalmente diferente do primeiro: em (1) deve-se ir para casa quando é tarde, em (3) não se deve ir para casa quando é tarde.

Em (4) $E$ tarde, mesmo assim vamos para casa, também ocorre um encadeamento transgressivo, com sentido totalmente contrário ao de encadeamento (2).

Percebe-se que o enunciado (2) é a forma transgressiva do enunciado (1), ou seja, transgride o sentido proposto em (1). E o enunciado (4) é transgressivo do (3). Assim, (1) e (2) pertencem a um mesmo bloco semântico, enquanto (3) e (4) pertencem a outro bloco semântico.

Com esses quatro enunciados, portanto, há possibilidade de formar dois blocos semânticos diferentes (cada qual com 4 aspectos), possibilidade essa que decorre da inserção do elemento de negação em (3).

A visualização desses dois blocos distintos, com os aspectos normativos e transgressivos de cada um deles, será apresentada no tópico seguinte. Antes, porém, vale dizer que embora os quatro enunciados apresentados sejam completamente aceitáveis, seria estranho que um enunciador tentasse sustentar mais de um discurso concomitantemente (a não ser que mudasse de idéia repentinamente). Assim, o enunciador que sustenta (1) (É tarde, portanto vamos para casa), provavelmente não sustenta, ao mesmo tempo, (2), (3), ou (4), mas os evoca, já que, conforme Carel, argumentar é convocar blocos semânticos.

Em outras palavras, um sujeito, ao proferir É tarde, portanto vamos para casa, por exemplo, o faz porque deseja sustentar a idéia de que se deve ir para casa quando é tarde. Utiliza um encadeamento semântico " $X$ portanto $Y$ " que expressa tal sentido. No entanto, ao utilizar esse encadeamento, evoca também, e as deixa em suspenso, as demais possibilidades semânticas (normativas e transgressivas) que se poderiam estabelecer entre os dois segmentos desse enunciado. Eis aí uma mostra da polifonia textual, noção essa que será melhor explorada a seguir.

\subsection{A Polifonia e os Blocos Semânticos}

Um dos conceitos fundamentais sobre o qual se erige a ADL é a polifonia. Para Ducrot, assim como para Bakhtin (2003) ${ }^{[9]}$, os enunciados são polifônicos, porque são dialógicos, ou seja, há sempre uma relação de diálogo entre um enunciado e outro. Quando se profere um enunciado, profere-se para responder (concordar, discordar, complementar, explicar, justificar...) outro. Por isso Bakhtin (2003) defende a idéia de que o discurso é sempre responsivo.

Nessa mesma linha de pensamento, Ducrot entende que o autor de um enunciado não se 
pone en escena en el mismo enunciado un cierto número de personajes. El sentido del enunciado nace de la confrontación de esos diferentes sujetos: el sentido del enunciado no es más que el resultado de las diferentes voces que allí aparecen (1988, p. 16)

Além disso, os discursos (enunciados) não são inéditos, ao contrário, são repetições de discursos já proferidos ou escritos por outrem.

Podemos decir que todos nuestros discursos son repetición. No solamente lo que estoy diciendo en este momento es la repetición de otras conferencias que he dictado en otras partes, a su vez repetición de cosas que ya he dicho antes o leído en otro lugar, sino que en la conversación cotidiana la mayoría de las vezes no hacemos más que repetir cosas que hemos escuchado (DUCROT, 1988, p. 17).

Assim, ao mesmo tempo em que os discursos são dialógicos (responsivos), são também polifônicos, pois neles "ecoam", além da voz do locutor, outras vozes que os constituem historicamente e servem de base para o locutor constituir o "seu" discurso. A polifonia compreende, portanto, as outras "vozes" de um enunciado, ou seja, entende que num enunciado se inscrevem outros pontos de vista (que não do locutor) sobre a mesma questão.

Num enunciado como É tarde, portanto vamos para casa (normativo) há outras possibilidades polifônicas, responsivas. Por exemplo, um segundo locutor, que discordasse da argumentação, poderia dizer Não é tarde, portanto não vamos para casa (normativo). Uma terceira voz poderia dizer É tarde, mesmo assim não vamos para casa (transgressivo). E um quarto, Não é tarde, mesmo assim vamos para casa (transgressivo).

Todas as quatro têm como eixo semântico comum a concepção de que sendo tarde, deve-se estar em casa (quanto mais tarde, mais se deve estar em casa).

Essas quatro vozes, então, correspondem a quatro aspectos de um mesmo bloco semântico que recebe o nome de quadrado argumentativo e cuja esquematização é:

É tarde, portanto vamos para casa ß---------------------à Não é tarde, portanto não vamos para casa

Não é tarde, mesmo assim @ B--------------_------à É É tarde, mesmo assim não vamos vamos para casa para casa

No quadrado, segundo Ducrot (CAREL e DUCROT, 2005, p. 45-46), as relações estabelecidas entre os aspectos são de reciprocidade, conversão e transposição, assim:

ß----------à Aspectos recíprocos

Aspectos conversos

Aspectos transpostos

Essas relações argumentativas, definidas pelo jogo de conectores e da negação, correspondem às relações discursivas. Ou seja, são quatro possibilidades discursivas (responsivas) que se organizam em torno de um mesmo bloco semântico, de uma mesma argumentação.

Perceba-se, ainda, que há possibilidade de inserir um NÃO no encadeamento, assim: É tarde, portanto não vamos para casa. Mas perceba-se, também, que, nesse caso, o bloco semântico já não seria o mesmo que o do anterior. Se antes o sentido era de que sendo tarde, deve-se estar em (ou ir para) casa - quanto mais tarde, mais se deve estar em casa -, com a inserção do não o sentido se altera. O bloco semântico agora passa a ser a idéia de que, sendo tarde, não se deve ir para casa quanto mais tarde, menos se deve ir para casa. Por isso, não se pode "encaixar" essa argumentação no mesmo bloco semântico, sendo necessário criar um novo quadrado argumentativo - com seus quatro aspectos - que dê conta dessa nova relação. Assim: 
É tarde, portanto não vamos para casa (normativo)
B-

Não é tarde, mesmo assim não vamos para casa (transgressivo) -à Não é tarde, portanto vamos para casa

(normativo)

\section{TEXTO-PROPOSTA: ANÁlISE SEGUNDO A SEMIÓTICA E A TBS}

Explanados os pontos basilares de cada uma das teorias, passa-se ao objetivo principal deste estudo: realizar uma aproximação entre a Semiótica greimasiana e a TBS. Cabe lembrar que dos três níveis de estruturação textual propostos pela Semiótica, o que interessa nesse estudo é o nível fundamental, pois é nele que se concentram as duas idéias opostas que constituem a semântica de base do texto.

\section{Texto-proposta}

\section{Uma outra agricultura possível}

“O atual modelo de produção agropecuária em andamento no país e no mundo é insustentável. Tanto do ponto de vista ambiental, como do social e do econômico. É insustentável ambientalmente porque degrada os recursos naturais, contamina a água e o solo, destrói florestas e a fauna. No aspecto social, porque provoca uma grande exclusão no campo, com a expulsão de populações inteiras e a degradação dos valores culturais. E é insustentável economicamente porque é um modelo tão dependente da agroquímica - elevação significativa do custo da produção e preços estabilizados - que impede a reprodução econômica das famílias rurais.

A alternativa ao modelo agroquímico tem que responder a esses três elementos: ser sustentável ambiental, social e economicamente. Tem que produzir sem degradar os recursos naturais, permitir a valorização do saber popular; a participação e o protagonismo do agricultor e tem de gerar renda. A agroecologia permite construir essa via. Ela não é uma tecnologia, nem um sistema de produção. É uma ciência que aglutina um conjunto de outras ciências, permitindo uma visão holística, sistêmica, integrada." (Lino de David, ZH, 23/11/01)

\subsection{Análise segundo a Semiótica}

A semiótica propõe a organização de cada nível de estruturação textual com base numa semântica e numa sintaxe próprias. A semântica e a sintaxe do nível fundamental, portanto, serão apresentadas em separado nesse item, embora ambas se fundam (e confundam) na composição do sentido.

\section{a) Organização da semântica fundamental}

Nesse texto, já no nível discursivo, aparece de forma clara a oposição entre "modelo agroquímico" e "agroecologia". Num nível maior de abstração (fundamental), tem-se como organização semântica de base a oposição entre artificial versus natural. O artificial está representado, no nível superficial, pelo "modelo agroquímico" e o natural, pela "agroecologia".

Os dois elementos pertencem ao mesmo eixo semântico, compondo, cada um deles, um dos extremos desse eixo (natural•-------•artificial). Por isso são denominados termos contrários, ou opostos.

No texto, o elemento artificial aparece como disfórico, valorizado negativamente pelo autor. E o natural é valorizado positivamente, portanto é eufórico.

Perceba-se que essas categorias (euforia e disforia) já estão inscritas no texto, de acordo com o sentido pretendido pelo autor. No entanto, pode-se ter um outro texto (discurso) em que o elemento valorizado positivamente seja o artificial (agroquímico), por exemplo, uma propaganda de semente transgênica ou mesmo de um inseticida com princípios ativos químicos.

\section{b) Organização da sintaxe fundamental}

O conteúdo fundamental aparece, também, sob a forma de relações orientadas, que compõem 
a sintaxe desse nível. O texto acima se constrói sobre a oposição entre artificial e natural, orientada no sentido da passagem do artificial (agroquímico) para o natural (agroecologia).

O texto começa afirmando que há um modelo atual de agropecuária (afirma o artificial: agroquímico) e que este é insustentável (nega o artificial), para, a seguir, afirmar uma nova possibilidade (natural: agroecologia).

Assim, a sintaxe fundamental que organiza esse texto é a seguinte:

afirmação do artificial à negação do artificial à afirmação do natural

ou

artificial à não-artificial à natural

Estabelecidas essas relações, pode-se formar o seguinte quadrado semiótico:

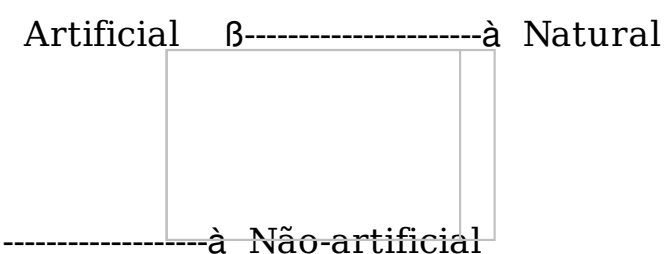

Lembrando que:

B------à contrários

contraditórios

complementares

Não-natural B--

As relações orientadas desse texto seguem o percurso:

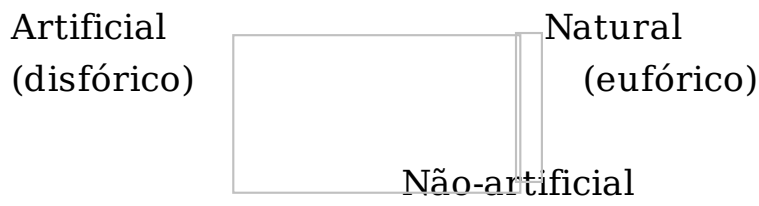

Já no caso da propaganda de semente transgênica, em que o "artificial" fosse o eufórico, as relações orientadas seguiriam o percurso inverso (natural à não-natural à artificial).

\subsection{Análise sob a ótica da TBS}

Já foi visto que a TBS propõe o encadeamento argumentativo como unidade semântica de base. Um texto, como se sabe, é constituído de muitos encadeamentos argumentativos, mas que se organizam e convergem para um sentido único, o sentido global do texto.

Assim, resumindo o texto-proposta num único encadeamento argumentativo semântico que dê conta do sentido global, tem-se:

Nosso modelo agropecuário é agroquímico, portanto é insustentável

ou

Nosso modelo agropecuário é insustentável porque é agroquímico

O bloco semântico que sustenta esse texto é a idéia de que quanto mais químico, mais insustentável/menos sustentável.

Com os aspectos argumentativos desse bloco, seria possível formar o seguinte quadrado argumentativo ${ }^{[10]}$ :

químico portanto insustentável B (normativo) -à não-químico portanto sustentável (normativo) 
Lembrando que:

B----à Aspectos recíprocos;

Se o discurso fosse a favor do artificial químico (caso da propaganda de semente transgênica) o encadeamento semântico básico não seria o mesmo. Poderia se afirmar, por exemplo, que exatamente por ser um modelo químico, possui maior sustentabilidade. Tal discurso possivelmente teria como encadeamento argumentativo "É químico, portanto é sustentável". Esse encadeamento faria parte de uma argumentação totalmente distinta da explicitada no quadrado acima. O bloco semântico seria diferente, uma vez que relacionaria ser químico com ser sustentável, estabelecendo interdependência semântica entre esses dois predicados (quanto mais químico, mais sustentável).

\section{TECENDO RELAÇÕES ENTRE SEMIÓTICA E TBS}

A primeira aproximação entre as duas teorias diz respeito ao fato de ambas serem estruturalistas. A semiótica propõe uma estrutura determinada, a partir da qual os textos se constroem: o percurso gerativo do sentido e a estruturação nos três níveis - fundamental, narrativo e discursivo -, cada um deles com uma sintaxe e uma semântica próprias, mas de cujas interrelações emergem os sentidos. O semioticista busca no enunciado as marcas da enunciação e, a partir delas, tece sua análise semântica. Também a TBS procede de forma estruturalista, uma vez que compreende que o sentido de um enunciado não está fora dele, mas nele próprio, nas marcas lingüísticas. Para a TBS o sentido argumentativo se dá no encadeamento argumentativo, que é uma unidade semântica básica. A exemplo do estruturalismo saussuriano, portanto, tanto Semiótica quanto TBS compreendem que o sentido emerge das relações entre unidades.

A segunda aproximação está relacionada ao fato de que ambas propõem unidades semânticas básicas como constitutivas dos enunciados/textos. A semiótica propõe como semântica fundamental (maior nível de abstração) de um texto uma unidade mínima de sentido que se resume na confrontação entre duas idéias contrárias (responsivas). No caso do texto-proposta, a confrontação entre natural versus artificial. A TBS trabalha com a concepção de encadeamento argumentativo como unidade mínima de significação. Assim, no caso do texto-proposta, o encadeamento argumentativo que resume o sentido é: Nosso modelo agropecuário é agroquímico, portanto é insustentável.

Aplicando a esse encadeamento os preceitos da semiótica, num nível de abstração maior, suprimindo as figuras e elegendo uma categoria mais abstrata e geral que englobe o sentido de "agroquímico", o encadeamento principal ficaria: Artificial, portanto insustentável. Nessa mesma direção, o sentido de "não-químico", no texto, corresponde a "natural". Assim, a oposição entre os aspectos normativos se dá no confronto entre: Artificial, portanto insustentável e Natural, portanto sustentável.

Ainda, quando se diz que o modelo agroquímico (artificial) é "insustentável", se atribui uma valoração negativa ao enunciado. E quando se diz que a agroecologia (natural) é sustentável, uma valoração positiva. Assim, na semiótica tem-se em uma das pontas do eixo semântico a categoria "artificial" = disfórica e na outra a categoria "natural"= eufórica. Na TBS, tem-se como normativos: Artificial, portanto insustentável e Natural, portanto sustentável. Ora, são duas formas análogas de estabelecer o sentido de base do texto/enunciado e a valoração positiva/negativa que os elementos de base recebem (nos termos Semiótica) ou a argumentação com que o locutor se identifica (nos termos da TBS).

Nessa mesma direção, mais uma analogia entre Semiótica e TBS: as duas teorias propõem a possibilidade de construção de quadrados semânticos. Estes, por sua vez, não seriam a materialização de possibilidades polifônicas? Em ambas as teorias, por meio dos quadrados, se evidenciam possibilidades responsivas dos discursos (textos/ enunciados). 
A semiótica entende que só se produzem discursos $\mathrm{X}$ porque existem discursos Y. Por exemplo, o texto-proposta defende a agropecuária baseada num modelo natural (ecológico) porque há discursos que defendem o modelo artificial (químico). Aí estão as duas "vozes" contrárias (polifônicas) de um mesmo eixo semântico.

A TBS deixa transparecer ainda mais a polifonia que subjaz aos discursos, o caráter responsivo destes. Enquanto a semiótica propõe duas idéias contrárias como semântica fundamental, a TBS possibilita a "visualização" de quatro possibilidades discursivas dentro de um mesmo bloco semântico, isso porque estabelece as possibilidades "transgressivas".

Comparem-se:

a) Quadrado semiótico do texto-proposta

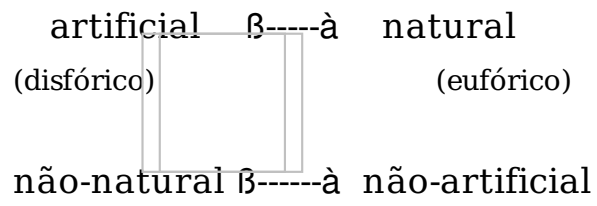

b) Quadrado argumentativo (TBS) do texto-proposta

\begin{tabular}{|c|c|c|}
\hline (normativo) & & (normativo) \\
\hline $\begin{array}{l}\text { Não-artificial mesmo assim } \\
\text { insustentável } \\
\text { (transqressivo) }\end{array}$ & B-----à & $\begin{array}{l}\text { Não-natural mesmo assim } \\
\text { sustentável } \\
\text { (transqressivo) }\end{array}$ \\
\hline
\end{tabular}

Na concepção da semiótica, o percurso feito pelo texto foi o seguinte: afirmação do artificial à negação do artificial à afirmação do natural. Só se afirma o natural porque há outros discursos que afirmam o artificial. Perceba-se, então, que, na semiótica, a polifonia se estabelece a partir de dois termos ditos contrários.

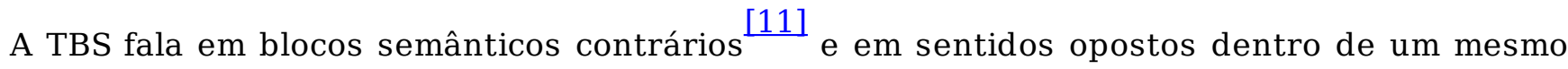
bloco ${ }^{[12]}$. Os dois encadeamentos normativos do texto (artificial, portanto insustentável x natural, portanto sustentável) estabelecem o sentido oposto um do outro. Através deles se instaura a mesma possibilidade polifônica instaurada pela análise semiótica.

Ao propor os encadeamentos transgressivos, porém, a TBS acrescenta mais duas possibilidades polifônicas do mesmo bloco semântico. Assim, se no texto-proposta o sentido é de que quanto mais artificial, menos sustentável (ou mais insustentável) e de que quanto mais natural mais sustentável - o sentido do texto-proposta é normativo --, há outros discursos, transgressivos, que remetem a outras possibilidades, como "artificial, mesmo assim sustentável" por exemplo uma propaganda de produtos plásticos biodegradáveis -, ou "natural, mesmo assim insustentável" - a exemplo de um discurso sobre a ineficácia da ação de um herbicida ecológico no combate às pragas da lavoura.

Uma última consideração aproximativa pode ser tecida entre os encadeamentos argumentativos da TBS com as idéias contrárias da semiótica. Levando em conta a semântica fundamental do texto-proposta, pode-se dizer que:

a) "artificial, portanto insustentável" = artificial disfórico

b) "natural, portanto sustentável" = natural eufórico

c) "não-artificial (natural) mesmo assim insustentável" = natural disfórico

d) "não-natural (artificial) mesmo assim sustentável" = artificial eufórico

Tecendo um só quadrado com base nas duas teorias:

A

artificial, portanto insustentável
B

natural, portanto sustentável 
natural , mesmo assim

natural disfórico
C

insustentáve]

ß-----à

$\mathrm{D}$

artificial, mesmo assim sustentável

artificial eufórico

Percebe-se que a relação entre os termos/aspectos A e B continua sendo de contrariedade (semiótica) / reciprocidade (TBS). Assim como a relação A/D, B/C continua sendo de contraditórios/conversos. Muda a nomenclatura, mas o sentido que se estabelece entre os segmentos é o mesmo. Portanto, as nomenclaturas "contrários/recíprocos" são equivalentes, assim como o são "contraditórios/conversos".

Assim também ocorre nas relações entre A/C e B/D. Para a TBS, ocorre entre A/C, B/D, uma relação de transposição, em que, segundo Ducrot (CAREL e DUCROT, 2005, p. 46), nega-se o primeiro termo, troca-se o conector e mantém-se o segundo termo (considerando que, no texto, "não-artificial = natural" e "não-natural = artificial"). Na semiótica, essa relação se dá entre termos/idéias complementares. Perceba-se que se preserva a relação de transposição, como também a de complementaridade. Afinal, é possível dizer que entre A/C (aspectos transpostos) há uma relação complementar no que tange à insustentabilidade independente do produto (artificial ou não-artificial = natural) utilizado, assim como entre $\mathrm{B} / \mathrm{D}$ se firma uma relação de sustentabilidade. "Aspectos transpostos" (TBS) e "termos complementares" (semiótica) são, portanto, equivalentes.

\section{ENFIM...}

Traçadas algumas semelhanças entre Semiótica e TBS, ficam as diferenças para um próximo momento. É certo que tampouco as semelhanças se esgotaram nesse breve estudo, o qual, longe de qualquer pretensão de esgotar o tema, teve como intuito apontar algumas percepções oriundas de práticas de interpretação textual aliadas a conhecimentos básicos de tais teorias. Para finalizar, importa destacar que não há prevalência de uma teoria sobre a outra, ao contrário, ambas são importantes enquanto perspectivas de semântica discursiva, e, nesse sentido, o domínio de preceitos básicos tanto da TBS quanto da Semiótica constitui instrumental precioso àqueles que se voltam ao estudo e ao trabalho com textos.

\section{REFERÊNCIAS}

BAKHTIN, Mikhail M. Estética da criação verbal. Tradução de Paulo Bezerra. São Paulo: Martins Fontes, 2003.

BARROS, Diana Luz Pessoa de. Teoria semiótica do texto. 4. ed. São Paulo: Ática, 2000.

CAREL, Marion; DUCROT, Oswald. La semántica argumentativa: uma introducción a la Teoría de los Bloques Semánticos. Edição realizada por Marta García Negroni e Alfredo M. Lescano. Buenos Aires: Colihue, 2005.

CAREL, Marion. O que é argumentar? Desenredo, Revista da PPGL da UPF, Passo Fundo, Ed. da Universidade de Passo Fundo, v.1, n.2, p.77-84, jul./dez. 2005.

DUCROT, Oswald. Polifonía y argumentación. Cali: Universidad del Valle, 1988.

FIORIN, José Luiz. Elementos de Análise do Discurso. 9. ed. São Paulo: Contexto, 2000. . A noção de texto na semiótica. Organon, Porto Alegre, v. 9, n. 23, p.163-173, 1995.

Introdução ao pensamento de Bakhtin. São Paulo: Ática, 2006.

[1] É preciso mencionar que não existe apenas a teoria semiótica francesa, mas também outras correntes de teorias semióticas que 
se desenvolvem em outros países, como nos Estados Unidos e na Rússia. Este trabalho, no entanto, baseia-se na teoria semiótica desenvolvida na França por ser esta a linha seguida tanto por Barros quanto por Fiorin, autores cujas obras serviram de embasamento para a realização deste estudo.

[2]

Não é objetivo deste trabalho fazer uma abordagem minuciosa da teoria semiótica e dos elementos que compõem cada um de seus níveis. Para um estudo mais detalhado da teoria, vejam-se Barros (2000) e Fiorin (2000).

[3]

O nível discursivo é o último nível do percurso gerativo do sentido, sob a ótica do produtor do texto. Opta-se, porém, por apresentá-lo em primeiro por ser este o percurso que o leitor traça.

[4] O nível narrativo é bastante complexo e envolve muitos outros aspectos que não serão apontados neste breve resumo. Para um conhecimento mais detalhado, vejam-se Barros (2000) e Fiorin (2000).

[5]

Sujeito e objeto não são representados, aqui, somente por pessoas e coisas. Sujeito é aquilo que sofre uma transformação, ou permanece, durante o decorrer do texto, num mesmo estado inicial; e objeto-valor é entendido como um "valor" com que o sujeito entra em comunhão, ou dele fica privado.

[6] ADL é a sigla constituída pela inicias do nome original da teoria: "Argumentation dans la langue”.

No artigo "O que é argumentar", Marion Carel (2005) deixa transparecer que não há uma definição única e consensual do termo "argumentação". Assim explicita que trabalha com a noção de argumentação discursiva, entendida como um encadeamento argumentativo em que dois segmentos sejam dependentes entre si.

Os conectores do tipo "portanto" recebem também a denominação francesa "donc"; e os transgressivos, a denominação "pourtant". No entanto, para evitar possíveis confusões entre os termos, serão utilizadas as expressões "portanto" e "mesmo assim".

[9] Para aprofundar conceitos de polifonia e dialogismo em Bakhtin, vejam-se as seguintes obras do autor: Estética da criação verbal (Martins Fontes, 2003) e Problemas de Poética em Dostoievski (Forense Universitária, 1981). Também o livro Introdução ao pensamento de Bakhtin (José Luiz Fiorin, Ática, 2006) aborda tais questões, principalmente o dialogismo.

[10] Por ora, trabalhar-se-á com os termos "químico" e "não-químico". No item subseqüente, entretanto, tais termos passam a ser englobados numa categoria semântica mais abstrata, como propõe a semiótica.

[11] Há blocos semânticos contrários (daí a possibilidade de 8 aspectos em torno de uma argumentação), conforme Carel e Ducrot (2005). Nesse caso, os contrários seriam os blocos artificial/sustentável x artificial/insustentável.

[12]

A relação de "contrários" apontada pela semiótica é denominada, na TBS, como relação de "recíprocos", vistos como opostos entre si (artificial portanto insustentável vs natural portanto sustentável). 